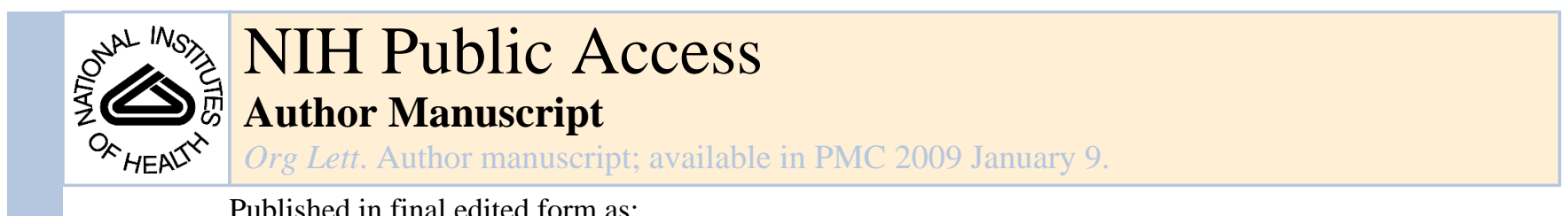

Org Lett. 2007 April 12; 9(8): 1613-1615. doi:10.1021/ol070449y.

\title{
Stereocontrolled Glycoside and Glycosyl Ester Synthesis. Neighboring Group Participation and Hydrogenolysis of 3-(2'- Benzyloxyphenyl)-3,3-dimethylpropanoates
}

\author{
David Crich and Feng Cai \\ Department of Chemistry, University of Illinois at Chicago, 845 West Taylor Street, Chicago, Illinois \\ 60607-7061
}

\begin{abstract}<smiles>CC[C@H](OC(=O)CC(C)(C)c1ccccc1OCc1ccccc1)[C@H](OCc1ccccc1)C(O)COc1ccccc1</smiles>

i) BocNH-L-Glu- $\alpha-\mathrm{O}-t-\mathrm{Bu}$, NIS, TfOH, $\mathrm{CH}_{2} \mathrm{Cl}_{2}$, rt, $90 \%$

ii) $\mathrm{Pd} / \mathrm{C}, 3 \mathrm{~atm} \mathrm{H}_{2}, \mathrm{rt}, 86 \%$

The 2-O-[3-(2'-hydroxyphenyl)-3,3-dimethylpropanoate] and 2-O-[3-(2'-hydroxy-4',6'dimethylphenyl)-3,3-dimethylpropanoate esters] enable the synthesis of a range of $\beta$-glucosides and $\alpha$-mannosides through neighboring participation in excellent yield, and are removed by hydrogenolysis in concert with the cleavage of benzyl esters in the presence of other esters making them particularly well suited to the stereocontrolled synthesis of glycosyl esters.
\end{abstract}<smiles>O=C(CC[C@@H](NC(=O)OCc1ccccc1)C(=O)OCc1ccccc1)OC(O)C(CO)C(O)CO</smiles>

The science of stereocontrolled oligosaccharide synthesis has advanced to a level at which targets of considerable complexity may be undertaken with confidence, ${ }^{1}$ permitting the development of actual therapeutic agents, ${ }^{2}$ as well as of clinical candidates, ${ }^{3}$ and even detection kits for biological warfare agents. ${ }^{4}$ With the potential for significant biomedical applications, efficiency becomes increasingly important, and one approach to this problem is through the development of minimalist protecting group strategies. We describe two related ester-type protecting groups, affording full stereocontrol through classical neighboring group participation under standard glycosylation conditions, which are cleaved by hydrogenolysis in concert with the removal of benzyl ethers. Following earlier work from our laboratory on the use of picolinyl esters in oligosaccharide synthesis, ${ }^{5}$ the $2-O$-picolinyl ethers have recently been introduced with similar aims in mind, ${ }^{6}$ however the low reactivity of the intermediate glycosyl pyridinium results in long reaction times and severely compromises the otherwise armed nature of these systems. ${ }^{7}$

Numerous studies have focused on the development of ester protecting groups that are cleaved other than by direct saponification. The typical strategy involves unmasking of a latent nucleophile which subsequently closes onto the ester carbonyl group with expulsion of the alcohol. A wide range of alcohol and amine deprotection methods have been adapted to this end, ${ }^{8}$ most classically the release of levulinate esters with hydroxylamine or hydrazine. ${ }^{9}$ 
Nevertheless, hydrogenolysis is largely missing from this list, with the exception of the 2-[2(benzyloxy)ethyl]benzoate esters for which base catalysis continued to be necessary for lactonization. ${ }^{10}$

Preliminary studies with 4-benzyloxybutanoate esters and their 3,3-dimethyl analogues revealed lactonization to be slow with respect to hydrogenolysis of the benzyl ether, and that the addition of base was necessary to promote cleavage, as had been found with the 2-[2(benzyloxy)ethyl]benzoates. ${ }^{10}$ The slow lactonization with these model systems led us to adapt the 3-(2'-hydroxyphenyl)-3,3-dimethylpropanoate and 3-(2'-hydroxy-4',6'-

dimethylphenyl)-3,3-dimethylpropanoate groups, for which very rapid cyclization of the corresponding anilides had been demonstrated by Amsberry and Borchardt. ${ }^{11}$ Perbenzylation of the hydroxy acids derived from $\mathbf{1}$ and $\mathbf{2}$ followed by saponification gave the acids $\mathbf{3}$ and $\mathbf{4}$, which were introduced onto the 2-OH of otherwise perbenzylated thioglycosides, by means of carbonyl diimidazolide, ${ }^{12}$ to give the glycosyl donors 5-7 in good yield (Scheme 1).

With 1-adamantanol and 2-propanol as model acceptors, various thioglycoside activation protocols were assayed for couplings to donors 5-7, with the NIS/trifluoromethanesulfonic acid protocol ${ }^{13}$ proving optimal. In all model reactions excellent coupling yields were matched by the observation of complete selectivity for the formation of the 1,2-trans-glycosides (Table 1, entries 1-3). Standard hydrogenolysis in ethanol over palladium/charcoal then afforded the fully deprotected systems. Importantly, hydrogenolysis was found to be slower than lactonization, such that no trace of esterified products was detected in these deprotections. Encouraged by these results we proceeded to carry out a further series of coupling reactions to typical carbohydrate acceptors (Table 1, entries 4-13).

Glycosylation reactions proceeded satisfactorily in almost all cases except for the attempted coupling of the somewhat hindered, less reactive acceptors methyl 3,4,6-tri- $O$-benzyl- $\alpha$-Dmannopyranoside and methyl 2,3,6-tri- $O$-benzyl- $\alpha$-D-glucopyranoside with donor 5 when poor yields were repeatedly obtained (Table 1 , entries 7 and 10). Fortunately, this situation was remedied by recourse to the less hindered donor 6 (Table 1, entries 8, and 11).

It is interesting to note that when greater than 1 equivalent of NIS is employed in the activation process the electron-rich TMBPP and DMBPP groups undergo iodination in the aromatic ring. This produces a series of glycosylated byproducts of polarity very similar to that of the anticipated products. These iodinated byproducts are formed with the same stereoselectivity as the iodine-free products and are not detrimental to the overall process as they are similarly cleaved by hydrogenolysis under the standard conditions.

We also directed our attention to the stereocontrolled synthesis of glycosyl esters with particular emphasis on the $\gamma$-glutamates, owing to the recent identification of an unusual $\beta-1,3$ glucan-glutamate ester moiety in the fungal cell wall Pir protein from Saccharomyces cerevisiae. ${ }^{14}$ Gratifyingly, NIS-mediated glycosylation was again high yielding and fully stereoselective. Hydrogenolysis of the glycosyl esters also proceeded smoothly with no detectable cleavage or migration of the glutamate esters (Table 2).

The results set out in Table 2 allow the possibility that hydrogen iodide, formed during the hydrogenolysis of iodinated byproducts present as minor impurities as alluded to above, catalyzes the lactonzation step to be discounted. This is because such catalytic quantities of HI would also be expected to cleave Boc groups and tert-butyl esters and reduce the yield overall, contrary to the experimental observations.

Overall, a method is presented for the stereocontrolled synthesis of glycosidic bonds through neighboring group participation, and for the removal of the participating ester groups by hydrogenolysis alongside benzyl ethers. Notably, the deprotection takes place in a single 
reaction step, in the complete absence of acid or base, and is tolerant of other esters and in particular of glycosyl esters.

\section{Supplementary Material}

Refer to Web version on PubMed Central for supplementary material.

\section{Acknowledgment}

We thank the NIH (GM62160) for support of this work.

\section{References}

1a). Recent syntheses:Crich D, Banerjee A. J. Am. Chem. Soc 2006;128:8078. [PubMed: 16771524] b) Crich D, Bowers AA. Org. Lett 2006;8:4327. [PubMed: 16956218] c) Kim Y-J, Wang P, NavarroVillalobos M, Rohde BD, Derryberry J, Gin DY. J. Am. Chem. Soc 2006;128:11906. [PubMed: 16953631] d) Taylor JG, Li X, Oberthür M, Zhu W, Kahne DE. J. Am. Chem. Soc. Asap e) Zhu X, Kawatkar SP, Rao Y, Boons G-J. J. Am. Chem. Soc 2006;128:11948. [PubMed: 16953636]

2. Petitou M, van Boeckel CAA. Angew. Chem. Int. Ed 2004;43:3118.

3a). Werz DB, Seeberger PH. Angew. Chem. Int. Ed 2004;44:6315. b) Wu X, Bundle DR. J. Org. Chem 2005;70:7381. [PubMed: 16122263] c) Ragupathi G, Koide F, Livingston PO, Cho YS, Endo A, Wan Q, Spassova MK, Keding SJ, Allen J, Ouerfelli O, Wilson RM, Danishefsky SJ. J. Am. Chem. Soc 2006;128:2715. [PubMed: 16492059]

4. Tamborrini M, Werz DB, Frey J, Pluschke G, Seeberger PH. Angew. Chem. Int. Ed 2006;45:6581.

5. Crich D, Dudkin V. J. Am. Chem. Soc 2001;121:6819. [PubMed: 11448186]

6. Smoot JT, Pomsuriyasak P, Demchenko AV. Angew. Chem. Int. Ed 2005;44:7123.

7a). Other stereodirecting protecting groups.Yamada T, Takemura K, Yoshida J.-i. Yamago S. Angew. Chem. Int. Ed 2006;45:7575. b) Kim JH, Yang H, Park J, Boons G-J. J. Am. Chem. Soc 2005;127:12090. [PubMed: 16117550] c) Kim JH, Yang H, Boons G-J. Angew. Chem. Int. Ed. 2005;44:947. d) Kulkarni SS, Liu S-H, Hung S-CJ. Org. Chem 2005;70:2808. e) Jiao H, Hindsgaul O. Angew. Chem. Int. Ed. 1999;38:346. f) Ziegler T, Pantkowski G. Liebigs Ann. Chem 1994:659.

8a). Utagawa E, Sekine M, Seio K. J. Org. Chem 2006;71:7668. [PubMed: 16995672] b) Yu H, Williams DL, Ensley HE. Tetrahedron Lett 2005;46:3417. c) Crimmins MT, Carroll CA, Wells AJ. Tetrahedron Lett 1998;39:7005. d) Trost BM, Hembre EJ. Tetrahedron Lett 1999;40:219. e) Thompson C, Ge M, Kahne D. J. Am. Chem. Soc 1999;121:1237. f) Ge M, Thompson C, Kahne D. J. Am. Chem. Soc 1998;120:11014.

9a). Grindley, B. Modern Methods in Carbohydrate Synthesis. Khan, SH.; O’Neill, RA., editors. Harwood Academic Publishers; Amsterdam: 1996. p. pp225Kocienski, PJ. Protecting Groups. 3rd Ed.. Thieme; Stuttgart, Germany: 2005. Greene, TW.; Wuts, PGM. Protective Groups in Organic Synthesis. 3rd ed.. Wiley; Hoboken: 1999. Guo, Z.; Xue, J. Reagents for Glycoside, Nucleotide, and Peptide Synthesis. Crich, D., editor. Wiley; Hoboken: 2005.

10. Watanabe Y, Ishimaru M, Ozaki S. Chem. Lett 1994:2163.

11. Amsberry KL, Borchardt RT. J. Org. Chem 1990;55:5867.

12. Ohta S, Shimabayashi A, Aono M, Okamaoto M. Synthesis 1982:833.

13a). Konradsson P, Udodong UE, Fraser-Reid B. Tetrahedron 1990;31:4313. b) Garegg PJ. Adv. Carbohydr. Chem. Biochem 1997;52:179. [PubMed: 9218334]

14. Ecker M, Deutzmann R, Lehle L, Mrsa V, Tanner W. J. Biol. Chem 2006;281:11523. [PubMed: 16495216]

Org Lett. Author manuscript; available in PMC 2009 January 9. 

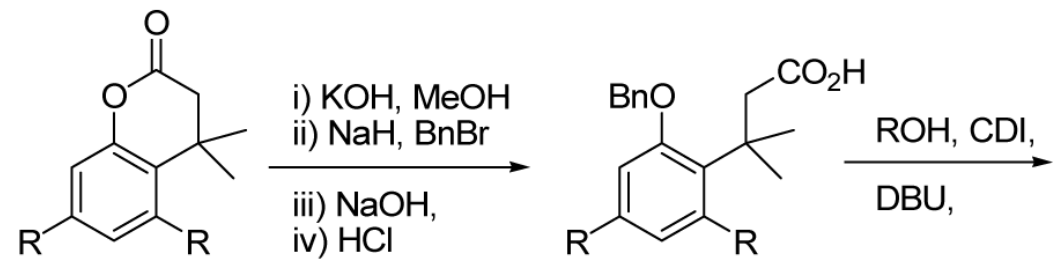

1: $R=M e$

2: $\mathrm{R}=\mathrm{H}$

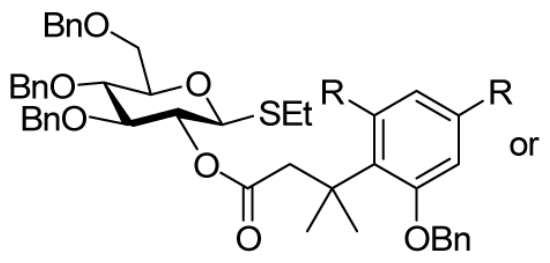

5: $\mathrm{R}=\mathrm{Me}, 87 \%$

6: $R=H, 88 \%$
3: $\mathrm{R}=\mathrm{Me}, 64 \%$

4: $\mathrm{R}=\mathrm{H}, 51 \%$

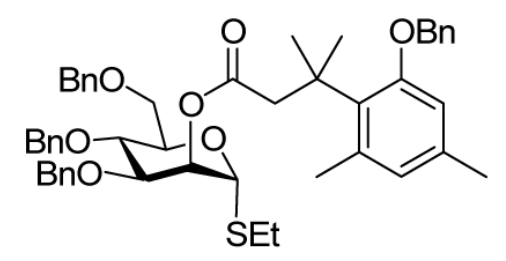

7: $88 \%$

Scheme 1.

Preparation of Donors 
Glycosylation of Alcohols ${ }^{a}$ )

Table 1

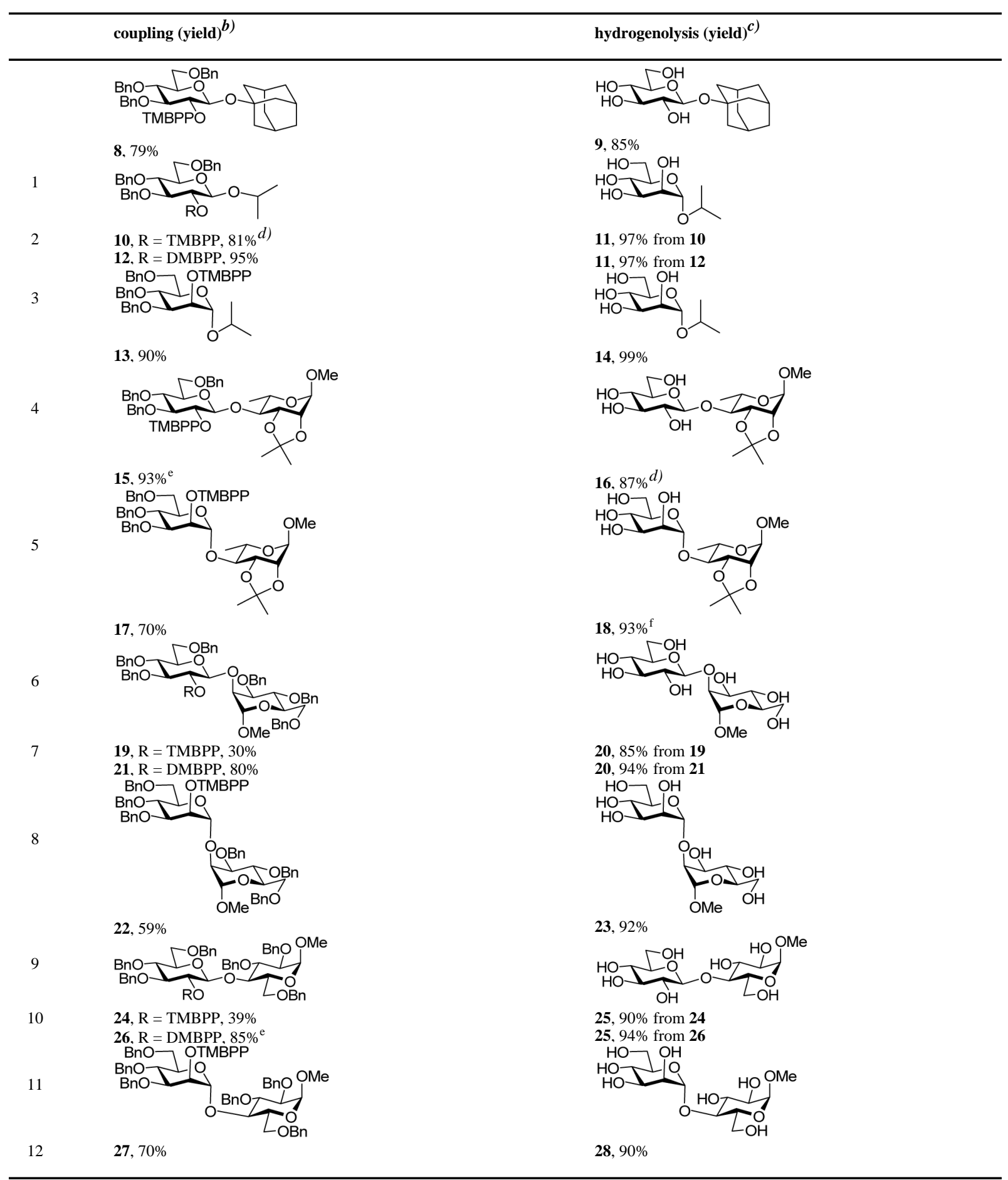

a) TMBPP: tetramethylbenzyloxyphenylpropionate; DMBPP: dimethylbenzyloxyphenylpropionate.

b) 1.5 Equiv of acceptor, 1 equiv of NIS, 0,3 equiv of $\mathrm{TfOH}$ in $\mathrm{CH}_{2} \mathrm{Cl}_{2}$ at $-40{ }^{\circ} \mathrm{C}$.

c) $20 \% \mathrm{Pd} / \mathrm{C}$ and $3 \mathrm{~atm}$ of $\mathrm{H}_{2}$ in $\mathrm{MeOH} / \mathrm{EtOAc}$ at room temperature. 
${ }^{d)}$ The hydrogenolysis was carried out with $20 \% \mathrm{Pd}(\mathrm{OH})_{2}$ as catalyst. 


\section{Table 2}

Glycosylation of $\gamma$-Glutamate ${ }^{a)}$

coupling (yield) $\left.)^{b}\right)$

a) TMBPP: tetramethylbenzyloxyphenylpropionate; DMBPP: dimethylbenzyloxyphenylpropionate.

b) 1.5 Equiv of acceptor, 1 equiv of NIS, 0,3 equiv of $\mathrm{TfOH}$ in $\mathrm{CH}_{2} \mathrm{Cl}_{2}$ at $-40{ }^{\circ} \mathrm{C}$.

c) $20 \% \mathrm{Pd} / \mathrm{C}$ and $3 \mathrm{~atm}$ of $\mathrm{H}_{2}$ in $\mathrm{MeOH} / \mathrm{EtOAc}$ at room temperature. 